CÓMO CITAR ESTE ARTÍCULO:

López, A.I. (2016). El uribismo y su carácter populista. Una reconstrucción de sus condiciones de posibilidad. Revista de Sociología y Antropología: VIRAJES, 18 (1), 87-107. DOI: 10.17151/rasv.2016.18.1.5

\title{
EL URIBISMO Y SU CARÁCTER POPULISTA. UNA RECONSTRUCCIÓN DE SUS CONDICIONES DE POSIBILIDAD*
}

\section{ÁLVARO IVÁN LÓPEZ BAYONA**}

Recibido: 15 de septiembre de 2015

Aprobado: 28 de septiembre de 2015

\author{
Artículo de Investigación
}

\footnotetext{
* Este artículo es resultado del proyecto de investigación "Patria y pueblo: un análisis del discurso político del uribismo en clave populista", el cual fue realizado para optar por el título de Magíster en Estudios Culturales en la Universidad de los Andes.

** Sociólogo, Magíster en Estudios Culturales. Docente Facultad Ciencias de la Comunicación Universidad Minuto de Dios. Correo electrónico: aibayona@hotmail.com; alopezbayon@uniminuto. edu.co (1) ORCID: 0000-0002-5600-4073
} 


\title{
Resumen
}

El propósito de este artículo es reconstruir las condiciones históricas que posibilitaron la aparición y constitución del uribismo como un movimiento populista en Colombia a principios del siglo XXI. En particular, el objetivo es demostrar que fueron tres circunstancias en particular: la institucionalización del neoliberalismo durante la década del noventa bajo el gobierno de César Gaviria Trujillo; la desinstitucionalización del Estado colombiano producto del escándalo de la infiltración de dineros del narcotráfico en la financiación de la campaña presidencial de Ernesto Samper Pizano; y el paso de la esperanza de la paz al recrudecimiento de la guerra bajo el gobierno de Andrés Pastrana; las que produjeron una crisis orgánica en la sociedad colombiana, que posibilitó la emergencia de un conjunto de demandas populares que propiciaron el surgimiento y consolidación del uribismo como una alternativa política en el país.

Palabras clave: crisis orgánica, uribismo, populismo, patria.

\section{URIBISMO AND ITS POPULIST NATURE. A RECONSTRUCTION OF ITS POSSIBILITY CONDITIONS}

\begin{abstract}
The purpose of this paper is to reconstruct the historical conditions enabling the rise and establishment of uribismo as a populist movement in Colombia at the beginning of the $21^{\text {st }}$ Century. Basically, the goal is to demonstrate that there are three particular circumstances: the institutionalization of neoliberalism during the 90s under the César Gaviria Trujillo administration; the deinstitutionalization of the Colombian State as a result of the drug trafficking moneys infiltration scandal for the funding of Ernesto Samper's presidential campaign; and the passing of peace hope into the war worsening under the Andrés Pastrana administration, which resulted in an organic crisis of the Colombian society making possible the emergence of a set of popular demands contributing to the rise and consolidation of uribismo as a political alternative in the country.
\end{abstract}

Key words: organic crisis, uribismo, populism, homeland. 


\section{Introducción}

Una de las condiciones fundamentales para la emergencia y consolidación de un movimiento populista, como lo destaca Reyes (2005), es la configuración de una crisis orgánica que "se manifiesta como una proliferación de demandas populares que no pueden ser neutralizadas por el marco de poder estatal existente" (138). Colombia, al finalizar el siglo XX e iniciar el XXI, experimentó este tipo de crisis, la cual tuvo como elementos configurantes el “deterioro progresivo de la situación de orden público y [el] debilitamiento institucional" (Arias, 2011, p. 184) del Estado colombiano, materializado esto en una creciente desconfianza hacia los dos partidos políticos tradicionales, el Liberal y el Conservador, como los únicos puentes efectivos de intermediación política entre las demandas de los ciudadanos y las soluciones ofrecidas a estos por parte del Estado; la incapacidad de éste y de los gobiernos anteriores para ofrecer a los ciudadanos seguridad y tranquilidad en todo el territorio nacional; y la crisis económica y social, la cual, para finales del siglo XX, tenía sumida a Colombia en un déficit fiscal superior al 55\% del PIB.

Bajo estas circunstancias surgieron un conjunto de demandas populares que desbordaron la capacidad institucional del Estado para dar respuesta a las mismas; es decir, sobrepasaron su capacidad de respuesta pasando de ser simples peticiones o constituirse en reclamos con cierto carácter subversivo. Una de estas demandas, la cual logró articular, es decir, unificar temporalmente a diferentes grupos y sectores sociales como fueron los indígenas, los afrocolombianos, las mujeres, los estudiantes, los empresarios y los sindicalistas, entre otros, fue la relacionada con la búsqueda de la paz y la construcción de "alternativas que pusieran término al conflicto armado" (Sandoval, 2007, p. 52) colombiano. Esta demanda, cabe señalar, no fue la expresión de una esencia común subyacente compartida por estos grupos, sino la resultante de una lucha y construcción política a partir de la cual estos se articularon de manera equivalencial en torno a la misma. Un hecho significativo que demuestra esta articulación, aunque de manera esporádica, fue la movilización realizada a finales del año 1999, cuando "unos 12 millones de colombianos marcharon por las calles y avenidas de las principales ciudades [del país] pidiendo paz" (Palacio, 2002, p. 673).

Otra demanda importante, asociada a la inseguridad y al conflicto armado colombiano, la cual comenzó a adquirir la dimensión de reclamo hacia finales del 2001, fue la necesidad de recuperar el orden constitucional y la autoridad del Estado colombiano en todo el territorio nacional, los cuales, como consecuencia del fortalecimiento militar de los grupos 
armados ilegales, fundamentalmente de la guerrilla de las Farc, habían sido seriamente cuestionados.

Frente a la corrupción, el clientelismo y la politiquería, la demanda que se formuló fue la consolidación de un Estado eficiente, eficaz y transparente, el cual se constituiría en un Estado de corte gerencial que lideraría la lucha contra "la deficiente gestión de autoridades municipales y los constantes indicios de corrupción en distintas entidades públicas" (CINEP, 2009, p. 10) del orden nacional, regional y municipal.

Por último, en relación con la profunda crisis económica y social, el reclamo se dirigió hacia la recuperación de la economía y la generación de mejores condiciones de vida. Una de las principales demandas dentro de este ámbito se orientó a la necesidad de frenar el aumento progresivo "de la desocupación y la caída de los ingresos" (Estrada, 2004, p. 104) de la gran mayoría de los colombianos; desocupación que para 1998 alcanzó la cifra de $18 \%$, la más alta en los últimos veinte años en Colombia. Otra demanda importante dentro de este ámbito fue la necesidad de disminuir el creciente déficit fiscal de la nación, el cual para 1999 ascendió a "niveles superiores al 55\% del PIB absorbiendo, a través de su servicio, cerca del $40 \%$ del presupuesto de los gastos de la nación" (p. 206).

Frente a este conjunto de demandas y la falta de respuesta efectiva por parte del orden institucional a las mismas, surgieron nuevos movimientos y partidos políticos como alternativas para la solución de las mismas. Algunos de estos, quizá los más representativos, fueron el Polo Democrático Alternativo y el movimiento Político Primero Colombia ${ }^{1}$, movimiento que cobijó en un principio las banderas del uribismo.

Bajo este conjunto de circunstancias se abrió el camino para que una "alternativa" política, una particularidad, lograra constituirse como la única "alternativa" viable que ofrecía soluciones "reales" o, por lo menos "creíbles" al conjunto de problemas que vivía la sociedad colombiana. Esta particularidad fue el uribismo. A continuación, cumpliendo con el propósito de este artículo, se reconstruyen algunas de las corrientes o circunstancias que posibilitaron la aparición de este y su posterior consolidación como el grupo medular dentro de la sociedad colombiana².

\footnotetext{
${ }^{1}$ Es importante señalar que este movimiento fue creado únicamente para respaldar la aspiración presidencial de Álvaro Uribe Vélez en el año de 2002 y para su reelección en el 2006. De igual manera, que una de las principales fundaciones que difunde el pensamiento uribista lleva su nombre. Esta fundación es el Centro de Pensamiento Primero Colombia.

${ }^{2}$ Esta denominación de grupo medular se toma de Grossberg (2004), quien lo define como un grupo que logra su unidad a través de la diferencia; es decir, que este es una alianza temporal y contingente de varias fracciones de diferentes grupos sociales que conforman su unidad a través de alianzas y no de coincidencias ideológicas. Otro aspecto clave de este grupo medular es que logra obtener el liderazgo político, moral e intelectual dentro de una determinada formación social por un tiempo definido, estableciendo de esta manera el sentido común a través del cual se entiende y hace el mundo social.
} 
No obstante, antes de emprender esta tarea es necesario realizar las siguientes aclaraciones con el propósito de señalar los alcances y límites de este artículo. En primer lugar, esta reconstrucción no es exhaustiva en la medida en que en esta no se desarrollan todas las corrientes o circunstancias que posibilitaron la constitución del uribismo como un movimiento populista en Colombia. Solamente se destacan algunas de estas $^{3}$. En segundo lugar, la delimitación cronológica, última década del siglo XX y primeros dos años del siglo XXI, se justifica en la medida que fue durante este período en el cual se presentaron tres de las circunstancias más significativas que abrieron paulatinamente el espacio político y social a un movimiento populista en Colombia. Por último, es importante aclarar que al entender al uribismo como un movimiento populista, es necesario alejarse de las interpretaciones clásicas que asocian al populismo a una forma irracional, vaga e indeterminada de movilización donde las masas -las plebs- son manipuladas por un líder carismático o un grupo social en contra de los "ricos" o "privilegiados", y de la perspectiva reivindicativa que lo explica como un movimiento de carácter popular reivindicativo, marcado por su ascendencia de clase; movimiento a través del cual se pretende implementar una forma de gobierno redistributiva que favorezca al pueblo -el populus- en contra de la oligarquía o burguesía.

La consecuencia de esta toma de posición respecto al análisis del populismo y su asociación al uribismo, es que este último puede es entendido como populista en la medida que fue el resultado de un proceso articulatorio de diferentes grupos y demandas sociales que se articularon alrededor de una demanda popular, la recuperación de la patria, la cual se instauró como el nuevo centro aglutinador de dichas diferencias ${ }^{4}$. Esto quiere decir que este no fue el resultado de una coincidencia ideológica entre grupos y sectores sociales homogéneos, sino la resultante de una articulación a través de la diferencia. Deigual manera, es importante recordar que este logró presentarse "a sí mismo como subversivo del estado de cosas existente y también como el punto de partida de una reconstrucción más o menos radical de un nuevo orden" (Laclau, 2005, p. 221) social, condición primordial señalada por Laclau de todo movimiento populista. Este nuevo

\footnotetext{
${ }^{3}$ Dentro de las circunstancias que no van a ser tenidas en cuenta, cabe señalar la conexión que se le atribuye al uribismo con el paramilitarismo, la cual, según diferentes estudios, sirvió como forma de presión para fortalecerlo como una fuerza hegemónica en algunas regiones del país, especialmente en los departamentos de Córdoba, Sucre, Bolívar, César, Magdalena y Antioquia.

${ }^{4}$ Es importante reconocer la importancia de la seguridad y la protección dentro de la consolidación del uribismo como movimiento hegemónico. De hecho, la Política de Seguridad Democrática implementada por Álvaro Uribe Vélez durante sus dos mandatos presidenciales, se constituyó en un pilar fundamental de su forma de gobernabilidad; sin embargo, nuestra tesis sostiene que estos dos elementos fueron articulados en uno más amplio, como lo fue la recuperación de la patria.
} 
orden social fue articulado alrededor de un nuevo sujeto popular: el pueblo patriótico.

\section{La institucionalización del neoliberalismo}

A comienzos de la década de los noventa la sociedad colombiana se incorporó de lleno en el proceso de institucionalización y profundización del modelo neoliberal como el modelo de desarrollo para el país. El encargado de llevar a cabo este proceso fue el gobierno de César Gaviria Trujillo (1990-1994), quien bajo la orientación de organismos internacionales como el Fondo Monetario Internacional (FMI), el Banco Mundial (BM), la Organización Internacional del Trabajo (OIT) y el Banco Interamericano de Desarrollo (BID), implementó toda una serie de reformas estructurales con el propósito de preparar el terreno para la reestructuración del Estado y la sociedad colombiana y la posterior liberalización y desregularización de su economía.

Dentro de este clima reformista, el cual partía de la idea "de que la estabilidad macroeconómica se constituía en la condición [sino quo] para realizar lo que en adelante se llamarían reformas estructurales" (Estrada, 2004, p. 70); el gobierno de Gaviria, junto con la colaboración permanente del poder legislativo, construyó, presentó, defendió y sancionó una serie de normas, leyes y decretos con el propósito fundamental de ofrecer un marco normativo, legal y constitucional que brindaría total legitimidad al proceso de neoliberalización del Estado y la sociedad colombiana.

Dentro de este esfuerzo, fueron la formulación y posterior aprobación de un cierto número de leyes lo que permitió normativizar los elementos económicos del neoliberalismo dentro de un orden jurídico constitucional. Algunas de estas leyes, quizá las más importantes, fueron la Ley 50 de 1990 a través de la cual se realizó una reforma laboral que flexibilizó la jornada de trabajo; la Ley 45 de 1990, por medio de la cual se realizó una reforma financiera que permitió, entre otras cosas, comenzar una privatización progresiva y sistemática de los bancos estatales; la Ley 30 de 1992, a través de la cual se reestructuró la educación superior, convirtiendo a esta en un servicio medido en términos de eficiencia, eficacia, costo y beneficio; la Ley 100 de 1993, por medio de la cual se creó el sistema de seguridad social integral, estableciendo la salud como un servicio y no como un derecho fundamental; y, por último, la Ley 142 de 1994, por medio de la cual se dio una organización mercantil a los servicios públicos domiciliarios (2004), sustrayendo al Estado de la función social y económica que él mismo, dentro de un modelo regulacionista, debía cumplir. 
A su vez, los objetivos de este entusiasmo neoliberal se concretaron en cinco puntos fundamentales: en la necesidad de reducir a como diera lugar los costos de la fuerza de trabajo; en impulsar el flujo de capital productivo y especulativo; en permitir la libre explotación de los recursos naturales; en estimular la expansión del capital financiero; y en reducir drásticamente los controles y la participación del Estado colombiano en todo tipo de actividad económica (desregulacionismo).

Bajo este clima reformista el gobierno de Gaviria avanzó, como muy bien lo señala Estrada, "de manera significativa hacia la llamada desregularización de la economía [sentando] las bases para el proceso de reforma neoliberal" (74) del Estado y la sociedad colombiana. Este clima reformista estuvo acompañado e impulsado por un contexto internacional que jugó un papel decisivo en la institucionalización del neoliberalismo en Colombia. Dentro de este contexto internacional, dos acontecimientos fueron los de mayor importancia: el fin de la guerra fría y el viraje dado por Estados Unidos en su política internacional hacia América Latina.

Con respecto al fin de la guerra fría, se puede señalar que la caída de los regímenes político-comunistas de la Europa oriental hacia finales de la década de los ochenta y del comunismo como un modelo alternativo al modo de producción capitalista, dio el impulso necesario para que el neoliberalismo lograra establecerse como el modelo de desarrollo universal y "deseable" para toda la "humanidad". Al ser presentado el neoliberalismo por teóricos neoliberales como Friedrich von Hayek, Milton Friedman y Francis Fukuyama como el punto culminante del capitalismo y el comunismo como un rezago histórico correspondiente a un modelo obsoleto y ahistórico -el fin de la historia-, el neoliberalismo encontró un terreno propicio para alcanzar el grado de universalización necesario como el único "modelo expresivo de [...] la transición hacia una nueva fase de la transnacionalización del capital o de la 'globalización capitalista' a escala planetaria" (9). En otras palabras, el neoliberalismo logró establecerse como el modelo universal y universalizable, mientras el comunismo o cualquier otro tipo de modelo alternativo al capitalismo se representaron como modelos ahistóricos y obsoletos, resultado de una fase previa de la historia humana.

El argumento principal del cual se valieron los teóricos neoliberales para encumbrar al neoliberalismo como la etapa culminante del capitalismo y desprestigiar al comunismo o al socialismo como modelos intervencionistas y obsoletos, fue una crítica férrea a la intromisión del Estado en la economía, es decir, una crítica devastadora al Estado de bienestar, ya fuera este de orientación liberal, conservadora, comunista o socialista. Esta intervención, de acuerdo con los teóricos neoliberales, impedía a la economía capitalista 
alcanzar su "verdadero" potencial: la liberalización de todas las fuerzas productivas.

Otro argumento que sirvió para sustentar la superioridad del neoliberalismo sobre cualquier otro modelo fue la articulación equivalencial entre libertad política y libertad económica. Para los teóricos neoliberales, "el fundamento de la libertad política se encontraba en la libertad económica" (p. 35); es decir, el fundamento de la libertad política y, por lo tanto, de cualquier otro tipo de libertad se fundamentaba, según la teoría neoliberal, exclusivamente en la libertad económica, la cual se constituía, de esta manera, en la base para estructurar cualquier tipo de organización social moderna. En otras palabras, sin libertad económica, según los teóricos neoliberales, no existía la más mínima posibilidad de alcanzar la libertad política, social o cultural. Según esta racionalidad, sin libertad económica no existía la más mínima posibilidad de estructurar de forma ordenada y adecuada una sociedad moderna ${ }^{5}$.

El segundo acontecimiento internacional, el cual fue un efecto directo de la reconfiguración mundial, es decir, del fin de la guerra fría, fue el viraje dado por Estados Unidos en su política internacional hacia América Latina a finales de la década del ochenta. Este viraje consistió, esencialmente, en cambiar de estrategia política para mantener y consolidar el neoliberalismo como el modelo de desarrollo para los países latinoamericanos. En este punto es importante destacar, como lo señala Estrada, que si bien "la llegada del neoliberalismo a América Latina se inscrib[ió] en un principio dentro de la cruzada anticomunista internacional" (34), después, con la desaparición del comunismo como una amenaza real al capitalismo, esta presencia se reconfiguró alrededor de nuevos enemigos que se constituyeron como las nuevas amenazas al mismo. Al no existir la amenaza real del comunismo en los países latinoamericanos, con la única excepción de Cuba, la hegemonía estadounidense se vio obligada a reconfigurar toda una nueva serie de amenazas que colocaran en una situación de riesgo real o potencial al capitalismo. Estas nuevas amenazas fueron el narcotráfico, la corrupción, la ineficiencia del Estado, la politiquería, el terrorismo, entre otras (Ramírez, 2004).

Un hecho de gran importancia dentro de esta nueva orientación, el cual marcó el nuevo tipo de relación entre Estados Unidos y los países latinoamericanos, fue la realización en 1989 de una reunión en Washington en la cual participaron varios funcionarios del FMI, del WB,

\footnotetext{
${ }^{5}$ En este punto se puede señalar, siguiendo a Laclau (2005, 2005a), que el significante vacío que articuló el neoliberalismo como un proyecto hegemónico fue la demanda por la libertad económica, la cual inscribió dentro de sí otras demandas como la libertad política, social o cultural. El resultado de esta articulación fue que la libertad económica comenzó a significar algo más que su simple contenido literal.
} 
del BID, miembros del gobierno y del Congreso de Estados Unidos y varios intelectuales y tecnócratas de los países latinoamericanos. Esta reunión y el posterior documento resultado de la misma se conocen como el Consenso de Washington.

Este, en términos generales, se constituyó en un programa político que sintetizó un conjunto de "propuestas de política neoliberal y unas experiencias de políticas de ajuste estructural que se homogenizaron y se pretendieron generalizar en forma de un recetario" (Estrada, 2004, p. 41) para todos los países latinoamericanos. Este recetario, descontextualizado de las condiciones históricas, sociales, políticas, económicas y culturales de los países latinoamericanos, se centró fundamentalmente en los siguientes puntos $^{6}$ : en la imposición de una férrea disciplina fiscal a los gobiernos de turno; en el establecimiento de cambios en las prioridades del gasto: se dio prelación al pago de la deuda, dejando a un lado el gasto social; en la realización de reformas tributarias orientadas a buscar bases impositivas amplias y tipos marginales moderados; en la liberalización financiera, especialmente de los tipos de interés; en la búsqueda y mantenimiento de la estabilidad de precios y de tipos de cambio competitivos; en la profundización de la liberalización comercial; en la apertura a la entrada de inversiones extranjeras; en las privatizaciones de las empresas estatales; en la desregularización de la economía por parte del Estado y en el aseguramiento de los derechos de propiedad.

Como puede observarse estos puntos se materializaron de forma ordenada, juiciosa y diligente durante el gobierno de César Gaviria Trujillo en las leyes anteriormente reseñadas; es decir, que durante este gobierno el recetario formulado por el Consenso de Washington se constituyó en el punto central que marcó la formulación e implementación de toda la política económica y social en el país.

El resultado de la implementación de este recetario fue el establecimiento de las bases de un modelo concentrador en lo económico y excluyente en lo social, por medio del cual se privilegió la apertura comercial, el libre movimiento de capitales, el desmonte de las funciones socio-económicas del Estado y la obsesión por el equilibrio fiscal (De la Torre, 2005); todo esto, en claro detrimento de las clases medias y los más pobres.

\footnotetext{
${ }^{6}$ Este documento fue elaborado por John Williamson, quien sintetizó los elementos más importantes de dicha reunión en 10 puntos bajo el título "Lo que Washington quiere decir cuando se refiere a reformas económicas" (1990). Esta reunión tuvo como propósito fundamental realizar un balance de las políticas neoliberales, hasta el momento implementadas en los países latinoamericanos y reorientar, de esta manera, las políticas de ajuste estructural que se ejecutarían en los siguientes años.
} 
Los efectos de este modelo se mostrarían hacia finales de la década de los noventa e inicios de este siglo, cuando la concentración del ingreso registró un crecimiento vertiginoso, desequilibrado e inequitativo. Las siguientes cifras son ilustrativas al respecto: "mientras en 1990 el decil más rico tenía ingresos cuarenta veces mayores que el decil más pobre, en 2001 dicha proporción subió a ochenta veces, producto de la concentración del ingreso en el 3\% de la población" (Estrada, 2004, p. 206). De igual manera, hacia finales de la década de los noventa la sociedad colombiana asistió "a un preocupante incremento de la deuda pública (cerca de 40.000 millones de dólares)" que registró, para el año de 1998, "niveles superiores al 55\% del PIB absorbiendo, a través de su servicio, cerca del $40 \%$ del presupuesto de los gastos de la nación"; del mismo modo, "la tasa de desocupación aumentó a cifras cercanas al 18\% y el subempleo afectó al 30\% de la población económicamente activa" y "la pobreza -medida de acuerdo con los ingresos- castigó al 68\% de la población colombiana, estimada en 44 millones" (206) de habitantes.

El resultado de la tan anhelada institucionalización del modelo neoliberal como el modelo de desarrollo para el país, como puede apreciarse, fue todo lo contrario a lo que se esperaba en un comienzo: en lugar de disminuir la deuda pública, esta aumentó a niveles inimaginables; en lugar de disminuir los índices de pobreza, estos aumentaron de forma exponencial; en lugar de realizar una redistribución equitativa del capital, este quedó en manos de unos pocos; y en lugar de hacer un Estado más eficiente y eficaz en su accionar, este creció en dimensiones desproporcionadas, constituyéndose en un estado burocrático, ineficiente e ineficaz.

Este conjunto de elementos, junto a otras circunstancias, generaría la emergencia y profundización de una crisis orgánica hacia finales de la década de los noventa, que se constituiría en la principal condición de posibilidad para la emergencia y constitución del uribismo como el grupo hegemónico dentro la sociedad colombiana.

\section{La desinstitucionalización del Estado colombiano}

Al finalizar el periodo presidencial de César Gaviria Trujillo, quien asumió la presidencia de Colombia fue el candidato por el Partido Liberal, Ernesto Samper Pizano (1994-1998). Samper, aunque trató de desmarcarse del impulso neoliberal de su antecesor, tuvo que dedicar gran parte de sus esfuerzos y de su tiempo, como lo señala Ramírez (2004), a defenderse de las acusaciones que se formularon en su contra por la financiación de su campaña presidencial con dineros provenientes del narcotráfico, más específicamente del Cartel de Cali. 
Los efectos de este escándalo no se hicieron esperar y tuvieron serias repercusiones para la institucionalidad del Estado y la sociedad colombiana. Un primer efecto de este escándalo fue un debilitamiento del Estado, el cual perdió legitimidad y capacidad de articular en torno a una demanda, como lo pudo haber sido la lucha contra el narcotráfico o la inversión social, a un grupo significativo de diferentes grupos y sectores sociales. Como lo señala Pécaut (2003), ni el Estado, ni el gobierno durante este período "logró unir a la sociedad [ni] a la dirigencia política en torno a algo que se asemejara a un propósito nacional"' (p. 42). Respecto a este punto, es importante señalar que la incapacidad del gobierno de articular a ciertos grupos sociales alrededor de un objetivo común, "fue rápidamente aprovechada por las guerrillas y los paramilitares para extender su presencia e intensificar sus ataques" (Ramírez, 2004, p. 193) en gran parte del territorio nacional. Por ejemplo, en el año de 1995 las Farc intensificaron su accionar militar y lograron propinar duros golpes a la fuerza pública; mientras que los paramilitares se unificaron y "trazaron una estrategia común de crecimiento y expansión territorial" (p. 193).

Otro efecto de la asociación entre Estado y narcotráfico fue que el primero comenzó a ser percibido por la comunidad internacional, especialmente por Estados Unidos, como un estado fallido (Nasi, 2007). Esta asociación resultó nefasta para la institucionalidad colombiana en la medida que uno de sus efectos fue una especie de habituación a la crisis política (Sandoval, 2007) desatada por este escándalo.

Un tercer efecto de este escándalo, asociado directamente al anterior, fue la pérdida internacional de legitimidad del Estado colombiano. La descertificación otorgada por el gobierno de Estados Unidos al gobierno colombiano en su lucha contra el narcotráfico, fue una clara respuesta del primero frente a la supuesta infiltración de dineros del narcotráfico a la campaña presidencial de Samper. Esta descertificación maniató al Estado frente a temas económicos, políticos y militares, ya que los recursos destinados por Estados Unidos a Colombia tuvieron una seria disminución. Esto, junto al recrudecimiento de la violencia política, profundizó aún más la crisis económica que golpeó a la sociedad colombiana hacia finales de la década de los noventa. Como lo señala Estrada (2004), el resultado de esta crisis fue que a partir de 1997 "los problemas de las finanzas del Estado se agravaron y adquirieron los rasgos de un déficit fiscal en ascenso; de igual manera, se apreció un sensible aumento de la desocupación y de la pobreza" (p. 104), lo cual se manifestó en una creciente inviabilidad económica, política y social del país frente a los países extranjeros.

Un último efecto de la debilidad institucional del Estado fue el deterioro y escalonamiento progresivo del conflicto armado y el 
fortalecimiento militar y económico de las guerrillas, las cuales, "mucho más fuertes económicamente gracias a los recursos del narcotráfico" (Sandoval, 2007, p. 144), desplazaron de sus prioridades la búsqueda de respaldo político hacia un escalonamiento bélico del conflicto armado que les permitiera emprender acciones armadas de mayor envergadura. El propósito de esta estrategia, como lo señala Sandoval, fue obtener cierta capacidad militar que les permitiera presionar al gobierno y a la sociedad colombiana, respecto a la necesidad de aceptar un posible diálogo de paz enmarcado dentro de sus demandas y exigencias.

No obstante, la respuesta por parte del gobierno de Samper fue el establecimiento en 1996 de las denominadas zonas especiales de orden público en los departamentos de Vaupés, Guaviare, Meta, Vichada y Caquetá, zonas de influencia guerrillera. Sin embargo, esta iniciativa no logró propiciar un acuerdo nacional alrededor de un rechazo profundo hacia las Farc o hacia los grupos armados ilegales como resultado de la "escasa legitimidad" (Ramírez, 2004, p. 194) de la cual gozaba el gobierno nacional. Todo lo contrario, el desconcierto, el desaliento y la dispersión de los sectores dirigentes ante la situación fueron persuadiendo a muchos colombianos que en el país no existía un liderazgo político, moral e intelectual capaz de enfrentar y resolver los problemas nacionales, la crisis del gobierno y del Estado y, en particular, el conflicto armado (193).

La conjunción de los anteriores factores generó un clima generalizado de desconfianza hacia el gobierno de Samper que se tradujo en una profunda incapacidad para gobernar el país durante sus cuatro años. Como lo señala Estrada (2005), "la crisis política, desatada por la financiación por parte del narcotráfico de la campaña electoral de Samper para llevarlo a la presidencia, tuvo como resultado un gobierno débil, dispuesto a hacer todo tipo de concesiones con el fin de poder terminar su cuatrienio presidencial" (96) sin mayores contratiempos. Esta situación de ingobernabilidad o, más bien, esta necesidad de negociar y realizar ciertas concesiones ante diferentes sectores sociales, como fueron los militares, los empresarios o los políticos para no profundizar aún más la crisis política, produjo un Estado permisivo, maniatado y débil que abrió la compuerta para que los grupos armados ilegales, las Farc y las AUC fundamentalmente, lograran consolidarse en diferentes regiones del país como fuerzas beligerantes o paraestatales, con la suficiente capacidad bélica y política para disputarle a este el monopolio legítimo de la violencia y representación política de los ciudadanos.

Fueron estas circunstancias las que abrieron "las puertas para que la población se decidiera por un próximo candidato más proclive a la paz" (Sandoval, 2007, p. 145), que se desmarcara de escándalos de corrupción, 
que no presentara vínculos con personas $\mathrm{u}$ organizaciones asociadas al negocio del narcotráfico, que lograra restablecer las relaciones diplomáticas con Estados Unidos y que ofreciera soluciones factibles a la profunda crisis política y económica que vivía el país. Este candidato fue el conservador Andrés Pastrana Arango.

\section{De la esperanza de la paz al recrudecimiento de la guerra}

La llegada de Pastrana a la presidencia de Colombia (1998-2002) se explica, entre otras razones, por la capacidad articulatoria que logró producir una demanda particular como lo fue la necesidad de alcanzar la paz entre diferentes sectores y grupos sociales que apoyaron su aspiración presidencial. Esta demanda logró inscribir dentro de sí misma todo un conjunto de demandas sociales particulares y diferenciales como lo fueron la recuperación económica, la necesidad de reestructurar los partidos políticos y la prioridad de reestructurar el Estado colombiano. De hecho, como bien lo señala Ramírez (2004), el éxito de la campaña presidencial de Pastrana se debió, en alto grado, a la capacidad articulatoria que logró producir una propuesta política sustentada fundamentalmente en la necesidad de emprender una política de paz con los grupos guerrilleros colombianos, que abriera las puertas a una salida negociada al conflicto armado. Esta demanda fue la que se constituyó en el punto articulador de la política del gobierno de Pastrana durante su período presidencial.

Esta alcanzó su materialidad jurídica a través de la Ley 418 de 1999 (Ley de Orden Público) por medio de la cual se decretó el despeje militar de un área de 42.000 kilómetros cuadrados que comprendió los municipios de La Uribe, Mesetas, La Macarena y Vista Hermosa en el departamento del Meta y el municipio de San Vicente del Caguán en el departamento del Caquetá; esto con el propósito principal de emprender un diálogo de paz con la guerrilla de las Farc.

Sin embargo, esta iniciativa tuvo serios reclamos, rechazos y temores por ciertos sectores sociales, específicamente un sector de los militares y empresarios, quienes no estuvieron totalmente de acuerdo con que se realizara esta concesión. Estos se mostraron siempre reticentes a emprender cualquier tipo de acercamiento de paz que tuviera como condición previa ceder una parte del territorio nacional a un grupo guerrillero. El argumento bajo el cual se sustentó este rechazo fue una concepción de soberanía nacional, en la cual ceder una parte del territorio nacional al control de un grupo armado ilegal, se constituía en un claro mensaje a la sociedad colombiana de la incapacidad del Estado para vigilar, controlar y mantener el orden público en todo el territorio nacional. 
Esta actitud, y la poca atención del gobierno nacional a la misma, produjeron un ambiente tenso entre las fuerzas militares y el ejecutivo, siendo este último acusado por algunos sectores de las fuerzas armadas como un gobierno sumiso a las exigencias de la guerrilla de las Farc. No obstante, y a pesar de estos reclamos, temores y resistencias, la zona de despeje militar fue oficializada el 7 de julio de 1999 tras la instalación de las mesas de negociaciones entre el gobierno de Pastrana y las Farc. A partir de esta fecha y durante más de dos años, hasta el 20 de febrero de 2002, fecha en la cual se rompieron las negociaciones de paz y se decretó la nulidad de la zona de despeje militar, el gobierno de Pastrana y las Farc mantuvieron una serie de reuniones con la intención de construir un proyecto de nación donde las demandas de la guerrilla tuvieran cabida.

Con la culminación de esta iniciativa de paz, la cual obedeció, entre otras razones, a las continuas acciones de la guerrilla contra la infraestructura del Estado colombiano, al aumento de sus ataques contra el ejército y la policía, al aumento del secuestro como arma de guerra y extorsión y a su incursión cada vez mayor en el negocio del narcotráfico, se daría por terminado, como lo señala Pécaut (2003), un período de "tres años de esperanzas y frustraciones, queda[ndo] un paisaje de guerra más cruel que antes, con el trasfondo de una descomposición social visible por doquier" (45).

Este contexto nacional, asociado al contexto internacional, incidió de manera significativa en el debilitamiento y posterior rompimiento de los diálogos de paz. La presión de Estados Unidos sobre el gobierno colombiano para que este obtuviera mayores resultados en su lucha contra las drogas y los atentados del 11 de septiembre de 2001 contra las torres gemelas en Nueva York y el Pentágono, fueron dos hechos centrales en esta dirección. De hecho, se puede afirmar que a partir del 11 de septiembre de 2001 la lucha contra los grupos armados ilegales colombianos se inscribió dentro de la agenda mundial de la lucha contra el terrorismo liderada por Estados Unidos.

Frente a esta situación nacional e internacional, el gobierno de Pastrana, con la intención de contrarrestar el aumento de la desconfianza en la opinión pública "en relación con el camino adoptado por [su] gobierno de negociar en medio de un conflicto que se agudizaba cada día más" (Ramírez, 204, p. 251); emprendió, junto con la colaboración de ciertos sectores del gobierno estadounidense, la tarea de convencer al congreso de este país para redireccionar los recursos que este había otorgado al gobierno colombiano para la lucha contra el narcotráfico en la modernización de las fuerzas militares; esto con el propósito fundamental de articular esta lucha a la lucha contrainsurgente. 
Esta iniciativa fue cobijada bajo el Plan Colombia, el cual le permitió al gobierno colombiano obtener recursos económicos, técnicos y humanos para preparar a las fuerzas militares en la lucha contra la insurgencia y el narcotráfico, de manera simultánea. Un dato importante de esta reorientación fue que el gobierno colombiano se convirtió en el tercer receptor internacional y el primero latinoamericano de ayuda estadounidense, siendo solamente superado por países como Egipto e Israel. Este dato demuestra el gran interés de Estados Unidos en mantener un aliado incondicional en el continente latinoamericano en su lucha contra las drogas y el narcotráfico.

La ayuda destinada por el gobierno de Estados Unidos hacia Colombia para el año 2001 fue de US $\$ 860.300$ millones, los cuales estuvieron distribuidos de la siguiente manera: asistencia militar US\$519.200; asistencia Policía Nacional US\$123.100; desarrollo alternativo US\$68.500; promoción de derechos humanos US\$51.000; fortalecimiento de las instituciones US $\$ 45.000$; ayuda a desplazados US $\$ 37.005$; reforma judicial US $\$ 13.000$ y búsqueda de la paz US\$3.00077.

Fue este contexto político, social y económico desfavorable el que le impidió al gobierno de Pastrana alcanzar su propósito central de conseguir una salida negociada al conflicto armado colombiano; por el contrario, bajo este se profundizó aún más la crisis social, política y económica que venía viviendo el país años atrás. Esta situación sería la propicia para la emergencia de un movimiento populista como el uribismo dentro del espacio político y social colombiano.

\section{De la conquista de los corazones a la conquista del Estado}

Como se ha evidenciado hasta el momento, Colombia entró al siglo XXI sumida en una profunda crisis orgánica como resultado de la incapacidad del orden social existente de resolver de manera diferencial, es decir, administrativamente, una serie de demandas democráticas particulares. Dentro de este contexto de crisis orgánica fue una demanda particular, la recuperación de la patria, la que logró estructurar, sobre la base negativa de que todas las demandas permanecían insatisfechas, la constitución de una nueva identidad política como el centro estructurador de un nuevo orden social. Esta nueva identidad fue el pueblo patriótico.

Un dato significativo referente a la constitución de este nuevo centro aglutinador fue el triunfo y consolidación que logró Álvaro Uribe Vélez, la encarnación del uribismo, en las elecciones presidenciales de los años 2002 y

\footnotetext{
${ }^{7}$ Estas cifras fueron tomadas de Socorro Ramírez (2004).
} 
2006. En el 2002, por ejemplo, este logró ganar las elecciones presidenciales en primera vuelta con un total de 5.862 .655 votos; es decir, con el 53\% del total de votos con una participación del $46,47 \%$ del censo electoral, hecho que se repetiría en las elecciones de 2006 con un total de 7.397.835 votos, $62,35 \%$ del total de votos con una participación del 45,05\% del censo electoral. Estos dos acontecimientos, si bien se refieren a un mecanismo formal democrático (guerra de posición en términos de Gramsci), indican la fuerza e importancia que adquiriría este grupo social como movimiento político en la construcción del futuro del país ${ }^{8}$ (guerra de maniobra en términos de Gramsci).

En este sentido, para explicar esta configuración del uribismo como fuerza hegemónica, es importante abordar la forma cómo Álvaro Uribe Vélez, la encarnación de este, logró situarse simbólicamente por fuera de la esfera política tradicional, y evidenciar la importancia que adquirió la apelación a la patria como un símbolo de unidad y lealtad en la configuración del pensamiento y accionar del mismo; es decir, en la forma como el uribismo logró conquistar los corazones y mentes del pueblo colombiano.

Respecto a la ubicación simbólica que logró construir Uribe como un político diferente a los demás, constituyéndose como alguien alejado de la esfera política tradicional, es importante resaltar, como lo señala Galindo (2007), que logró auto-representarse como una figura "alejada de la estructura institucional y de la cultura política de los partidos tradicionales" (p. 158) al realizar una crítica a los elementos característicos de esta, en otras palabras, al Estado burocrático, a la politiquería, a la corrupción y a sus promotores, adhiriéndose al pueblo colombiano como un cuerpo organizado alrededor de valores social cristianos. Algunos de estos valores, los cuales se constituyeron en la piedra angular del liderazgo moral llevado a cabo por el uribismo, fueron la solidaridad y la austeridad.

Este tipo de demarcación y remarcación simbólica se puede rastrear en algunos de los pronunciamientos de Uribe. Por ejemplo, en el siguiente apartado del texto "Mano firme, corazón grande. El camino de la confianza" (2002), Uribe sostuvo que soñaba con construir un "Estado al servicio del pueblo y no para provecho de la corrupción y la politiquería", ya que: "Hoy el Estado es permisivo con la corrupción, gigante en politiquería y avaro con lo social", sosteniendo que "El Estado burocrático y politiquero ha engañado al pueblo con un discurso social que no ha cumplido porque los recursos se han ido en clientelismo y corrupción". (p. 38). Sin embargo, esta operación no se agota en la crítica o denuncia, ya que la misma trasciende

\footnotetext{
${ }^{8}$ En efecto es significativo en la medida que desde la expedición de la Constitución Política de 1991, ningún candidato presidencial había logrado obtener la victoria en la primera vuelta presidencial.
} 
a la formulación de una posible solución apoyada fundamentalmente en construcción y consolidación de un Estado comunitario, el cual, en las propias palabras de Uribe, debía tener como tarea fundamental "construir ciudadanía para que hagamos el tránsito de masa a pueblo cohesionado con solidaridad" ya que "El compromiso de los colombianos con valores éticos que nos obliguen, como mínimo, a no hacer daño al prójimo es indispensable para la construcción de ciudadanía (p. 38).

El resultado de la demarcación de las lógicas políticas tradicionales y el establecimiento de una posible solución, fue la producción de una frontera antagónica por medio de la cual se dividió el espacio social colombiano en dos polos: por un lado, el pueblo o los sectores populares, en el cual se inscribió Uribe; y por otro lado su enemigo, en este caso la clase dirigente, los políticos tradicionales, el estado corrupto, politiquero, ineficaz, avaro en lo social y derrochador. Esto lo pudo realizar gracias a la producción, reproducción y circulación de un discurso político anti statu quo -populistapor medio del cual se simplificó "el espacio político [colombiano] mediante la división simbólica de la sociedad entre el pueblo y su otro" (Panizza, 2005, p. 13); discurso que a su vez posibilitó la constitución del uribismo como un nuevo sujeto político dentro de la sociedad colombiana. Dentro de este proceso, la apelación a la patria jugó un papel fundamental.

Una de las ideas que tuvo mayor incidencia en la configuración del uribismo fue la patria. Por un lado, esta se instituyó como un "destino de sacrificio y servicio surgido de una elección existencial al alcance de todos, más allá de las divisiones sociales y de las pertenencias étnicas, religiosas, lingüísticas" (Losonczy, 2006, p. 120), económicas y culturales presentes en la sociedad colombiana; y, por otro, como un espacio simbólico de identificación colectiva el cual no se redujo "al suelo apropiado, utilizado y habitado" por la población colombiana, sino que se extendió, "a través de modalidades muy diversas, a todos los espacios envueltos en la memoria, la invención o la reinvención de la tradición" (p. 134) y el futuro9.

Un ejemplo de la forma cómo operó la patria como ese centro aglutinador de las múltiples diferencias sociales, se puede observar a través de las siguientes intervenciones realizadas por Uribe. Por ejemplo, en el 2010 este se dirigió a los gremios empresariales y sindicalistas afirmando que "cualquier diferencia de matiz, de aproximación tiene un elemento que

\footnotetext{
${ }^{9}$ Estas dos formas de operar de la patria estuvieron asociadas a un sentimiento "colectivo de apego y solidaridad" (Losonczy, 2006, p. 66) -patriotismo- por medio del cual se logró congregar de manera universal a las múltiples diferencias presentes en la sociedad colombiana, por ejemplo, al obrero, al empresario, al campesino, al negro, al indígena, etc., alrededor de un ideal común: la recuperación de la patria. Su principal resultado fue la constitución de "posiciones de sujetos distintas de las de clase" (Mouffe; Laclau, 1985, p. 97), como fue el sujeto patriótico.
} 
la sintetiza, que es la patria" (2010b), equivaliendo dichas diferencias de matiz, diferencias de clase, a un elemento sintetizador: la patria. De igual manera, en 1999 Uribe señaló que "La seguridad, como concepto social, es para defender la vida y los derechos de todo el pueblo de la patria, de campesinos, obreros urbanos, líderes sindicales, jóvenes de las barriadas populares, industriales de las ciudades y empresarios del campo" (1999, p. 78), operación a través de la cual logró equivaler, es decir, articular en un solo sujeto -"el pueblo de la patria"- a un conjunto de posiciones diferenciales como fueron los campesinos, obreros urbanos, líderes sindicales, jóvenes de barridas populares, industriales de las ciudades y empresarios del campo.

Otras dos expresiones que permiten reafirmar esta centralidad de la patria en el discurso del uribismo fueron pronunciadas en el consejo comunitario número 199 realizado en mayo de 2008 en Florida, Valle del Cauca. En este consejo, Uribe rechazó de manera contundente la posibilidad de realizar un despeje militar en los municipios de Pradera y Florida, evocando en la memoria del pueblo colombiano una de las funciones de la patria como espacio simbólico de identificación colectiva, el fracaso de la anterior zona de despeje y las implicaciones negativas que esta tuvo sobre la población: "si les entregamos a esos bandidos lo que quieren, vuelven a secuestrar al país entero, empezando por los ciudadanos de Pradera y Florida" (2008a). Continuando con esta negativa, reafirmó que "el país no le puede entregar un milímetro al terrorismo, todo milímetro de la patria es para el trabajo, para el progreso, para la vida tranquila de los colombianos, no para el terrorismo" (2008a).

Respecto a estas dos expresiones, se puede señalar que a través de estas se reafirmó, aún más, una frontera antagónica en la cual los grupos guerrilleros fueron representados como los enemigos del pueblo: "los secuestradores del país", y la patria se representó como ese lugar destinado "para la vida tranquila de los colombianos", en el cual estos podían desarrollar su trabajo y alcanzar el progreso. Es decir, la patria se reinventó como un espacio simbólico a ser alcanzado, a través del cual se produjo una nueva identificación colectiva: el pueblo patriótico, los buenos colombianos, en contra de otra identidad: los malos colombianos.

\section{Conclusión}

En síntesis, se puede señalar que "Colombia entra al siglo XXI en un clima de violencia muy agudo y con un gran déficit social" (Arias, 2001, p. 169), económico y político, resultado de la institucionalización y profundización del modelo neoliberal como el modelo de desarrollo para el país, de la 
desinstitucionalización del Estado colombiano como resultado de la infiltración de dineros del narcotráfico en la presidencia de Ernesto Samper Pizano y, por último, de la agudización y profundización del conflicto armado y la consecuente deslegitimación del Estado como el garante de la seguridad en todo el territorio nacional.

A su vez, los principales resultados de estas tres circunstancias se materializaron en el aumento de una sensación de desprotección e inseguridad en la vida y bienes de la gran mayoría de los colombianos, en un crecimiento desproporcionado de los índices de desempleo y en una violencia política como nunca antes vistos en el país (Palacios, 2002). Esta articulación de circunstancias sería la propicia para la configuración de una crisis orgánica, la cual, a su vez, propiciaría la "reconfiguración de las identidades políticas en Colombia" (Nasi, 2007, p. 163), abriendo el camino para la configuración de un movimiento populista articulado alrededor de un nuevo sujeto político y de una demanda articulatoria. Este nuevo sujeto fue el pueblo patriótico y la demanda la recuperación de la patria.

Por último, dicho sujeto y demanda fueron el efecto y la causa, respectivamente, del surgimiento del uribismo como un movimiento populista en Colombia, el cual, siguiendo las indicaciones realizadas por Laclau (2005a) no debe ser entendido como populista "porque en su política o ideología presente contenidos reales o identificables como populistas, sino porque muestra una determinada lógica de articulación de esos contenidos" (p. 52); es decir, porque es el resultado de una lógica articulatoria por medio de la cual diferentes demandas y sectores sociales distintos se articulan alrededor de una demanda popular que los congrega a todos. Fue precisamente esta forma de articulación equivalencial lo que constituyó al uribismo y lo elevó al rango de grupo medular -hegemónicoen la sociedad colombiana durante los años 2002-2010. Quizá dicha hegemonía se haya debilitado, pero esto no quiere decir que haya perdido totalmente su capacidad articulatoria. De hecho, su proyecto político aún pervive en el corazón y mente de muchos colombianos.

\section{Referencias bibliográficas}

Arias Trujillo, R. (2011). Historia de Colombia contemporánea (1920-2010). Bogotá: Universidad de los Andes.

CINEP. Centro de Investigación y Educación Popular. (2009). Informe Especial. La protesta social 2002-2008: en cuestión las políticas públicas de Uribe Vélez. Bogotá: Cinep.

De La Torre, C. (2005). Álvaro Uribe: neopopulista. Revista Número, No 44: 50 - 60. . (2005르. Álvaro Uribe o el Neopopulismo en Colombia. Medellín: La Carreta Editores.

Estrada Álvarez, J. (2004). Construcción del modelo neoliberal en Colombia. 1970-2004. Bogotá: Ediciones Aurora. 
Fajardo Aristizábal, M. (2009). Los 'uribistas`: ideología y cultura política ¿democrática? Tesis de grado para optar por el título de Magíster en Ciencia Política. Facultad de Ciencias Sociales, Departamento de Ciencia Política. Universidad de los Andes, Bogotá.

. (2010). Las cosas como son: ¿cómo puede ser el uribismo una ideología, si no hay homogeneidad coherente dentro de los uribistas? Revista Asuntos Públicos, No 4. Bogotá: Universidad de los Andes.

Galindo Hernández, C. (2007). Neopopulismo en Colombia: el caso del gobierno de Álvaro Uribe Vélez. Iconos, Revista de Ciencias Sociales, No 27. Quito: Facultad Latinoamericana de Ciencias Sociales.

Grossberg, L. (2004). Entre consenso y hegemonía: notas sobre la forma hegemónica de la política moderna. Tabula Rasa, 2. Bogotá: Universidad Colegio Mayor de Cundinamarca. . (2010). Estudios culturales. Teoría, política y práctica. Valencia: Letra Capital.

Laclau, E.; Chantal, M. (1985). Hegemonía y estrategia socialista. Hacia una radicalización de la democracia. Argentina: Fondo de Cultura Económica.

Laclau, E. (1977). Política e ideología en la teoría marxista. Capitalismo, fascismo, populismo. México D.F.: Siglo Veintiuno Editores S.A.

. (2005). La razón populista. Buenos Aires: Fondo de Cultura Económica.

. (2005ª). Populismo. ¿Qué nos dice el nombre? En. Panizza, F. (Comp). El populismo como espejo de la democracia. Buenos Aires: Fondo de Cultura Económica.

Losonczy, A. M.. (2006). La patria como categoría en el postcomunismo. Ensayos sobre Hungría y Rumania. Bogotá: Universidad Externado de Colombia.

Mouffe, Ch. (2005). El 'fin de la política' y el desafío del populismo de derecha. En: Panizza, F. (Comp). El populismo como espejo de la democracia. Buenos Aires: Fondo de Cultura Económica.

. (2007). En torno a lo político. Buenos Aires: Fondo de Cultura Económica.

Nasi, C. (2007). Derechización 'a la colombiana'en tiempos confusos: un ensayo especulativo. Colombia Internacional 66. Bogotá: Universidad de los Andes.

Panizza, F. (Comp). (2005). El populismo como espejo de la democracia. Buenos Aires: Fondo de Cultura Económica.

Palacio, M.; Safford, F. (2002). Colombia: país fragmentado, sociedad dividida: su historia. Bogotá: Editorial Norma Grupo.

Pécaut, D. (2003). Midiendo fuerzas. Balance del primer año del gobierno de Álvaro Uribe Vélez. Bogotá D.C.: Planeta.

Ramírez, S. (2004). Intervención en conflictos internos. El caso colombiano. 1994-2003. Bogotá: Universidad Nacional de Colombia, Instituto de Estudios Políticos y Relaciones Internacionales (IEPRI).

Reyes, O. (2005). Conservadurismo skinhead: un proyecto populista fallido. En. Panizza, F. (Comp). El populismo como espejo de la democracia. Buenos Aires: Fondo de Cultura Económica.

Sandoval Robayo, M. L. (2007). Diacrítica del terror. Terrorismo y antiterrorismo a la luz del pensamiento de Pierre Bourdieu. Bogotá D.C.: Tercer Mundo Editores.

Uribe Vélez, Á. (1999). La seguridad, la autoridad y la paz. Homenaje a los Generales Rito Alejo del Río y Fernando Millán. En: Vásquez Pérez, A. (Comp). Del escritorio de Uribe. Selección de textos. Medellín: IELA Instituto de Estudios Liberales de Antioquía. . (2002). Discurso de lanzamiento de candidatura. En: Fundación Centro de Pensamiento Primero Colombia. (Comp). Campaña presidencial de Álvaro Uribe Vélez. Bogotá D.C.

. (2008). Palabras del Presidente Álvaro Uribe durante la presentación del 'Pacto Social por un Nuevo Sindicalismo'. Recuperado el 05 de septiembre de 2011, del sitio web de la Presidencia de la República: http://web.presidencia.gov.co/discursos/discursos2008/ mayo/sindicalismo 01052008.html 
El uribismo y su carácter populista. Una reconstrucción de sus condiciones de posibilidad |

(2010). Palabras del Presidente Álvaro Uribe Vélez durante el almuerzo con gremios y sindicalistas. Recuperado el 05 de septiembre de 2011, del sitio web de la Presidencia de la República: http://web.presidencia.gov.co/discursos/discursos2010/julio/ gremios 28072010.html 